\title{
A SYSTEMATIC REVIEW OF BARRIERS TO PUBLIC SECTOR INNOVATION PROCESS
}

\section{EMRE CINAR}

Portsmouth Business School

University of Portsmouth

Professor PAUL TROTT

Portsmouth Business School

University of Portsmouth

Dr. CHRISTOPHER SIMMS

Portsmouth Business School

University of Portsmouth

\section{ABSTRACT}

This article provides a systematic review of the empirical literature on barriers within public sector innovation processes, based on data from 63 articles. We investigate the nature of barriers. The studies were analysed based on four dimensions of barriers: i) their classification; ii) their interrelations; iii) whether they play distinct roles within stages of innovation process and iv) whether they vary in the types of innovations. We develop an empirically based framework to capture the complex nature of barriers. For this purpose, a new classification is also introduced to show that interaction-specific barriers emerge during the collaborative innovation process. Significantly we identify that the nature of barriers are more complex than has previously been recognized: they differ in process stages and innovation types. Moreover, they show interrelations across the innovation process by reinforcing each other. The findings show there is an emphasis on organizational barriers and implementation phase studies. We conclude with a discussion on how future research use quantitative and cross-national methods to examine: (1) interaction specific barriers, in particular, barriers with businesses and political bodies (2) design and sustainment phases of innovation (3) interrelations between barriers. 


\section{INTRODUCTION}

The purpose of this research is to examine difficulties and problems within the public sector innovation (PSI) process. In the innovation literature, these are often labelled as innovation barriers (Hadjimanolis 2003; D'Este et al. 2012). Identifying and understanding these barriers is widely acknowledged as an important success factor in the management of the process (Van de Ven 1986; Borins 1998, 2014; Walker, Jeanes, and Rowlands 2001; Osborne 2002; Torugsa and Arundel 2016).

The innovation literature within the private sector context has benefited to great extent from the 'Community Innovation Survey' to investigate the characteristics of innovation barriers this has led to an accumulation of a body of academic knowledge about them (for instance Galia and Legros 2004; D`este, et al. 2011, Galia,Mancini and Morandi 2012; Blanchard, et al. 2012). Within PSI there have been recent attempts to measure PSI via wide surveys such as Innobarometer within EU and MEPIN within Scandinavian countries. A limited number of studies (e.g. Bloch and Bugge 2013; Arundel, Casali and Hollander 2015) utilised the responses to innovation barriers from these surveys in their analysis, however none of these studied the nature of barriers exclusively. Thus, to date the literature lacks a comprehensive understanding of the nature of barriers within the PSI process.

Our study focuses on understanding the barriers within the innovation process. Specifically our paper addresses the following questions:

1. What are the specific barriers within the PSI process and how can these barriers be classified?

2. How do the barriers differ between the key stages of the innovation process?

3. What are the interrelations between the various barriers?

4. How do the barriers within the process differ between technological and nontechnological innovations?

The first contribution of this review is methodological. Systematic reviews emerged as significant additions to traditional literature reviews as they can provide reproducible, transparent and standardised techniques to identify pertinent studies (Moher et al. 2009). Indeed it is noticeable that there have been an increasing number of systematic reviews (e.g. 
Tummers et al. 2015; De Vries, Bekkers, and Tummers 2016) published in the public management field. However, a comprehensive systematic review of barriers to PSI is missing.

The second contribution of our paper is to synthesize the fragmented research field on PSI due to the diverse policy areas: from health and education, to water management and foreign affairs. This paper systematically reviews this literature and provides an evidence-based overview regarding the barriers within the innovation process. This enables us to identify which parts have been well studied. This also provides a basis for our future research agenda.

The third contribution of our paper is to provide new insights into the nature of barriers. To date barriers have been considered as antecedents of innovation and predictors of outcomes (see Parna and von Tunzelmann 2007; De Vries, Bekkers, and Tummers 2016). This static view focusing solely on the classification of barriers has failed to capture all the aspects of barriers. In theory, the features of barriers were regarded as interrelated and distinct during the phases of the innovation process; and diverse in different types of innovations (Hadjimanolis 2003). We investigate how barriers differ along the stages of the PSI process and how barriers reinforce each other dynamically via an underlying mechanism. Finally, our research uncovers how barriers vary between technological and non-technological innovations. The existing classification of barriers as external and internal (see for instance Borins 2000a; Bloch and Bugge 2013) is over-simplistic and cannot capture multi-actor PSI (see Osborne and Brown 2011; Hartley, Sorensen and Torfing 2013; Torfing and Ansell 2016). This necessitates clarifying the criticality of barriers shaped by the relationship between organisations, politicians and citizens within the innovation process. We investigate these barriers independently according to the different partners involved, which sheds insight into what challenges exist for collaborative PSI.

Our findings also provide practitioners within the public sector with new understanding of the barriers, thus enabling them to manage the innovation process in a more effective and proactive manner.

For this systematic review, we define innovation as 'a process through which new ideas, objects and practices are created, developed or reinvented, and which are new for the unit of adoption (Walker, Avellaneda and Berry 2011). It is worth noting that we do not approach 
the concept of innovation in a normative positive way. Similarly, we do not approach the concept of barriers in a normative negative way.

The remainder of this article is structured as follows. The first section details the methodology used for the systematic review. The second section and its sub-sections detail the results of the systematic review, initially providing details of the studies included and subsequently exploring the nature of barriers by examining their types, process characteristics, interrelations, and distinct variations on types of innovation. Finally, from our findings, we reach conclusions and provide a research agenda on barriers to PSI.

\section{METHODOLOGY}

\section{Database Search}

Three strategies were used to identify eligible articles. First, we carried out an electronic search in Web of Science restricted to Social Sciences Citation Index (SSCI) in title, abstract and keywords of articles.

The term [innov*] was searched along with the terms for barriers: [obstacle* OR barrier* OR challeng* OR hinder* OR deter* OR difficult* OR bottleneck* OR problem* OR setback* OR hurdle* OR hamper* OR imped* OR obstruct*]. To define the public sector character of innovation we use the following terms: [municipal* OR "public administrat*" OR "public organi\$ation*" OR "public management" OR government* OR "public service" OR "local government*" OR "e-govern*" OR "egovern* OR governance OR "public sphere" OR "public sector"]. Public or policy entrepreneurship has been studied connected with innovation (Roberts and King 1996) and so we searched the terms for barriers and public sector with the combination of [entrepreneur*]. This strategy resulted in a total of 3,524 articles.

Second we selected EBSCO Business Source database which enabled us to search full text in particular journals, because it is evident that barriers were seldom mentioned in the abstracts of articles (Sandberg and Aarikka-Stenroos 2014). Public Management Review, Administrative Science Quarterly, Journal of Public Administration Research and Theory, Journal of European Public Policy, Educational Administration Quarterly, Policy Analysis and Management, American Review of Public Administration, Public Administration Review, Policy Studies Journal, International Public Management Journal, Review of Public Personnel 
Administration, Governance and Public Administration were searched for the same terms. These journals were selected as they are top ranking Public Administration journals within "SCIMAGO Journal Rank". Innovation Journal was included because of its special interest on PSI. Government Information Quarterly and Telecommunications Policy were selected to search as they have been publishing IT innovation studies. Same term strings were searched in title, abstract, keywords and full-text. This strategy produced 324 studies.

The final stage of the literature search involved asking experts in the area of PSI to review our draft list of articles and for additional studies. They helped us to identify 102 further studies. The last response from an expert was received in July 2016.

\section{Eligibility of Articles}

We employed 'Preferred Reporting Items for Systematic Reviews and Meta-Analyses' (PRISMA) approach (Moher et al. 2009) to identify eligible studies. The articles should meet the following five criteria to be included in the review:

- Field: Articles should study innovation in public sector. We define the public sector in accordance with OECD (2006): 'The public sector comprises the general government sector plus all public corporations including the central bank'.

- Topic: The studies included needed to provide details on the 'revealed barriers ' within any part of innovation process. Studies that investigated 'deterring barriers' (D'Este et al. 2012) causing organisations not to initiate the innovation process were excluded. Some articles, for instance Kraemer, Nikolajsen, and Gulis (2014) did not clearly distinguish between these barriers, and were hence excluded. In addition, studies should explore the revealed barriers organisations faced. Articles focused on solely individual innovation adoption process of users were excluded. Finally, we excluded studies reporting medical innovations within health organisations.

- Study design: We included only empirical studies because we aim to synthesise the empirical evidence instead of theoretical contributions. Secondly, we excluded systematic reviews to avoid duplications.

- Language: Only articles written in English were eligible.

- Year of publication: Articles were searched and included that were published in the period from January 1996 to March 2016. 
- Publication Types: Only international peer-reviewed journal articles were included.

\section{Review Method and Coding}

The authors screened 3950 studies, resulting in 63 studies finally being included in the review. The study selection method and process is presented in PRISMA flow chart diagram (See Figure 1) as follows. In the first stage the articles were assessed to determine whether they study PSI by screening title and abstracts. Articles in other languages were also excluded in this step. Secondly, we screened the full-text of the articles to assess whether the study would capture the barriers to PSI. The third stage involved reading the full-text of the remaining articles to assess whether the inclusion criteria of revealed barriers within the process had been met.

The final stage of the process involved each one of the authors independently coding the articles, which enabled us to code 282 text fragments on barriers within innovation process. Both a deductive and inductive approach was used during the coding process. We constructed an initial coding book for categories from former literature. The results and label alternatives were discussed in the meetings simultaneously-the code book was improved via additional codes. Furthermore, all of the authors coded the same ten articles and calculated inter-coder reliability (we had a result of $90 \%$ agreement). Although it may be claimed that this form of coding is subjective, as there are not always concrete borders between coded labels and categories, this method has been used in many systematic reviews as an analytical tool to extract data from qualitative and quantitative studies (see Stirman et al. 2012; Voorberg, Bekkers, and Tummers 2015; Tummers et al. 2015; De Vries, Bekkers, and Tummers 2016).

Figure 1: PRISMA flow diagram for literature review process

\section{RESULTS OF SYSTEMATIC REVIEW}

\section{GENERAL CHARACTERISTICS OF STUDIES}

In this section, we will report on the general characteristics of the identified studies.

Publication Year: 
Figure 2 presents the evolution of studies over selected time period of 1996-2016. While fifteen (23.8\%) studies were published between 1996 and 2009, the number of publications rapidly increased after 2009 and forty-eight (74.2\%) were published between 2009 and 2016. Around $20 \%$ of the reviewed studies were published in 2014.

Figure 2: Year of publication for articles included in the systematic review

\section{Countries:}

Twenty-two percent of studies included in the review were conducted in USA. The Netherlands was the second most studied country (17\%). The UK was the third most studied (14\%). Although most of the articles (87\%) studied Western countries, we also found a limited number of studies conducted in Africa, Asia and Middle East. On the other hand, only eight (13\%) of articles made cross-country comparisons, revealing a lack of such studies within the literature. It is worth noting that a single article explored an international innovation by EU Parliament (Susha and Gronlund 2014).

\section{Journals:}

The reviewed articles were published in forty-one different journals. The four journals providing the greatest coverage of the topic were: Public Management Review (6), The Innovation Journal (5), Government Information Quarterly (5) and Public Administration Review (4).

Policy Areas:

The reviewed literature covered innovation in various public policy areas. Healthcare and general government activities \& finance shared first place with sixteen ( $25 \%$ each) articles. They were followed by social affairs (7; 11 per cent) and criminal justice (6; 10 per cent). Education, water management and transport were other policy fields studied with lower frequencies. These figures also indicate that our search strategy covered the key policy areas for PSI.

Terms for Barriers: 
Within both the private and PSI literature a wide range of terms are used to refer to barriers (Sandberg and Aarikka-Stenroos 2014). Table 1 indicates that 'barrier' (for example Piening 2011) and 'challenge' (Knutsson and Thomasson 2014) are the most common utilised terms within reviewed articles. This was followed by the terms: difficulty, challenge, problem and obstacle, respectively.

Table 1: Terms utilised to describe barriers within studies

\section{THE NATURE OF BARRIERS}

In the following five sections, the answers to our research questions will be reported: the types of barriers (RQ1), process stages and barriers (RQ2), interrelations between barriers (RQ3). Finally, how they differ in information communication technology (ICT) innovations and non-technological innovations (RQ4) will be explained.

\section{A.TYPES OF BARRIERS}

The following section reviews the typology of barriers. The findings are divided into four main sections. The first section covers organisational barriers. This is followed by interaction specific barriers between innovation partners within the innovation process. The third section investigates barriers related to perceived characteristics of innovation. The fourth part explored contextual barriers.

\section{i. Organisational Barriers}

A large number of the barriers mentioned in the reviewed literature can be linked to the internal context in which the innovation takes place. Organisational innovation barriers were reported on 114 (40\%) occasions (See Table 2). The reviewed literature indicates that the most common type of organisational barrier relates to the administration of the innovation process activities. Innovation, whether it is generated first time or adopted from elsewhere within the public sector, is a process consisting of several activities and actors, and activities within the process "proliferate into diverse pathways" after the initiation (Walker, Jeanes, and Rowlands 2001). An initiative can suffer from failures or difficulties in administration of a number of varied activities within the innovation process. On 34 occasions, authors mentioned this type of barrier. Our findings in this area included: 
- Logistical problems, such as lack of training (Abuya et al. 2012), inadequate support for end users (Gardner et al. 2010), insufficient citizen visits (Rocque et al. 2014) were the most common administration barriers within the process.

- A new initiative may foster additional workload for employees and managers. As a result they may prefer performing routine operations instead of innovation activities. This was evident in the cases of Florida`s novel Medicaid program (Landry, Lemak, and Hall 2011) and process innovation in a German hospital (Piening 2011).

- High staff turnover can also hinder the innovation process. Gardner (2010) exemplified this as "the constant flow of staff in and out" where remote health organisations tried to implement a managerial innovation in Australia. Similarly, Baltimore City suffered from $40 \%$ of management turnover in agencies during the adoption of a new performance management system (Sanger 2008).

Our findings on ineffective management also identified a number of other barriers, including top-down managerial thinking (Bernardes, Cummings, Évora, et al. 2012), lack of intraorganisational coordination (Bloch and Bugge 2013), ambitious or unclear goals (Gil-Garcia, Chengalur-Smith, and Duchessi 2007), inadequate incentives (Wigfall, Monck, and Reynolds 2006), lack of leadership (Brown 2010), slow decision-making (Hansson, Ovretveit, and Brommels 2012) and losing enthusiasm (Borins 2000a), each of which was related to ineffective administration of the innovation activities.

\section{Table 2: Organisational barriers}

The second organisational barrier was a resistance or lack of support from specific actors, which was mentioned as a significant internal barrier within the general innovation literature. Rogers (2003) suggests that this is stimulated by the uncertainty of new organisational conditions. Resistance by staff, managers or any other organisational resistance (NedovicBudic and Godschalk 1996; Plotnikof 2015), along with conflicts and opposition in the organisation (Ezzamel et al. 2014), represent common examples of resistance to change. Moreover, absent or inadequate support from these members of staff was identified as another key barrier (Bartlett and Dibben 2002). 
The third organisational barrier identified was a lack of available resources in terms of money, time and IT infrastructure. Specifically, a lack of national and state funding (Levine and Wilson 2013), shortage of staff (Weber et al. 2014) and limited information technology infrastructure (Bazemore, Phillips, and Miyoshi 2010) could hamper the innovation. The source and type of funding varied considerably across countries and contexts, and was usually not specifically stated within the reviewed papers. We attempted to code funding problems stemming from other organisations or political levels separately and display below under interaction specific barriers.

Fourthly, inappropriate organisational structure and culture was identified as barrier. A risk averse culture, in accordance with recent theoretical articles (Brown and Osborne 2013), was uncovered as a barrier to the innovation journey in many articles (Termeer 2009; van Buuren and Loorbach 2009). Rent seeking culture (Sabbat 1997; Azad and Faraj 2011), slow bureaucracy (Bakici, Almirall, and Wareham 2013), hierarchy (Susha and Gronlund 2014), and a lack of organisational learning culture (Marsden et al. 2011) were identified as road bumps within the process.

The final barrier coded was a lack of skills, knowledge and expertise, which makes the innovation process within public sector organisations more difficult (Raus, Fluegge, and Boutellier 2009; Wigfall, Monck, and Reynolds 2006).

\section{ii. Interaction-Specific Barriers}

Many scholars suggest that interactions within the innovation process enhance PSI (Bommert 2010; Sørensen and Torfing 2011). Yet, innovations involving multiple actors are not straightforward. The innovation journey frequently includes public organisations, contractors, citizen groups and NGO`s, political entities, and even international organisations (Hartley, Sørensen, and Torfing 2013; Osborne and Brown 2011). Hadjimanolis (2003) categorised these types of barriers as external, and claimed that they cannot be influenced by the organisation. However, these obstacles are embedded within the actors of the innovation process as they are in a dynamic relationship. The barriers that emerge between these parties cannot be described as internal or external, because they are formed during the interaction and may be affected by both parties. Thus, they should be investigated in detail and under an independent category according to the different parties involved. For instance, lack of shared 
understanding between collaborators or network members is a barrier which is influenced by both collaborators. We explored and coded these barriers under the category of "interactionspecific" barriers, and categorised them according to interaction partners.

\section{Table 3: Interaction-Specific Barriers}

Table 3 displays interaction barriers are reported in 84 (30\%) occasions. This reflects the collaborative nature of PSI. The most common experienced interaction barriers were between PSOs. These were followed by problems with citizens \& NGOs, enterprises as contractors and politicians or political entities. The interactions of PSOs with businesses and international organisations produced the least number of barriers. We distinguished contractors from businesses as users \& co-creators. We viewed contractors as the supplier of services or products for profit, whilst the latter are more involved in the process as users or co-creators of innovation.

\section{Public Sector Organisations}

The most frequently occurring interaction barriers identified within our review were between public sector organisations, which were found on twenty-nine (35\%) occasions.

A lack of shared understanding was the most frequently identified of interaction-specific barriers, when public organisations join together to innovate. This type of barrier emerges when PSOs cannot agree on common goals, common decisions, common vision and mission; which are necessary parts of "developing a shared understanding" (Ansell and Gash 2008). This is not an easy task, because organisations and citizens tend to negotiate their own interests (van Buuren and Loorbach 2009). Examples of the lack of shared understanding occurred between two ministries over the sustainment of funding (e.g. Cramer, Dewulf, and Voordijk 2014), between a city and sub-municipality about the location of a novel water plaza in Rotterdam (e.g. Biesbroek et al. 2014) and between health agencies about goal consensus of a new health program in Florida (e.g. Landry, Lemak, and Hall 2011).

The second interaction barrier was a lack of effective network governance. This theme underlined the importance of 'effective alignment and adjustment of partners` actions `which is vital while innovation is being generated and implemented (Sørensen and Torfing 2016). 
Accomplishing this network governance ineffectively represents a significant barrier in the process and reported in the literature quite frequently (Aagaard 2012). Thirdly, our review highlighted the critical influence of inadequate communication and knowledge sharing between public organisations, which can decelerate the innovation process as well (Dorado and Vaz 2003). Further, an educational policy innovation in Boston was hindered because Boston Public Schools did not share the student evaluation data with the innovation coordinator organisation (Levine and Wilson 2013).

The fourth most common interaction barrier was the lack of involvement by the essential organisations, which can make the innovation process more challenging. For instance, general practice surgeries could not be involved in the cancer network innovation process in NHS England despite all efforts, and this hampered reaching the target group (Martin, Currie, and Finn 2009). The fifth barrier highlighted related to funding. If the source of money for the innovation is another public institution, studies have highlighted that unreliable or interrupted funding can form a barrier within the process (Maluka et al. 2011). Indeed in some instances this may result in the funding of a project coming to an end (De Civita and Dasgupta 2007).

The sixth interaction barrier identified was inappropriate accountability between public sector organisations. These procedures may be too strict, too flexible or even absent in some cases (Ovseiko et al. 2014). For example, Maluka et al. (2011) reported that the lack of accountability over district health managers impeded the implementation of innovation. Seventh, our review revealed that the structure of the network holds the potential to form a barrier to innovation. In the case of Martin et al.`s (2009) study, a strict division between primary-care and hospital physicians for a cancer-network innovation within NHS acted as a barrier to innovation. In another case of an IT initiative, a fragmented transport system in Oslo exemplified a network structure problem impeding the innovation (Weber et al. 2014).

The eighth factor identified was 'turf fights' between agencies that slow the innovation. For example, Courts of Law in the Netherlands reacted to a proposed ICT innovation to hear the witnesses via video-link with suspicion because they perceived the innovation mandate by the ministry as an intervention to their "court independence" (Henning and Ng 2009). Finally, three additional barriers warrant note: The lack of trust between organisations (Pietroburgo 
2012), different organisational competences \& cultures (Termeer 2009) and the lack of mutual benefits (Aagaard 2012).

\section{Citizens and NGOs}

The interaction between citizens and government has always been central to public policy and administration. Whilst traditional public administration and New Public Management has regarded citizens as "subjects" or "clients", new public governance, labelled by Osborne (2006), foresees that citizens and their organisations engage in production of public services. This citizen engagement has been discussed in the literature via two terms: Co-production and co-creation. Our review uncovered that citizens and their related organisations produced the second most occurred interaction specific barrier whether their role was as: a (passive) user of an innovative programme, a client of an innovation, or co-innovators to generate, implement and sustain the novel initiative.

The most cited barrier in the category of citizens and NGO's is public doubt and opposition towards an innovation. For example, innovation initiatives in the Netherlands, which has a strong governance tradition (Kickert 1997), experienced this kind of opposition while they were attempting to design water management innovations (Biesbroek et al. 2014; van Buuren and Loorbach 2009). On the other hand, citizen barriers may emerge as user resistance to a novel service or product such as a procured novel chemical-free cleaning service for elderly care in Denmark (Zelenbabic 2015).

The second interaction barrier is related to the inadequate involvement of citizens or NGO`s. Meijer (2015) reports citizens' inadequate engagement to the CitizenNet program in the Netherlands. The programme proposed that they would form co-implementers of a novel police information collection system. This emerged as a barrier, due to citizens' reservations that they would become participants in law enforcement. In the case of quality management innovation, Plotnikof (2015) suggest that the local day care departments in Denmark suffer from inadequate public involvement as they were trying to design a quality management innovation. Further, Jing (2012) found that, within a new government initiative which attempted to fund social innovation proposals from a wide cross section of NGOs experienced problems, largely because these proposals primarily came from particular NGOs and thus failed to capture the needs of wider communities. 
There is evidence in our reviewed literature that the lack of shared understanding can hinder the innovation process when public organisations and citizens or NGOs cannot agree about goals, mission, and interests. For instance, Pietroburgo's (2012) study found that conflicting missions and goals, between the collaboration triangle of a city, a contractor, and an NGO, impeded innovative service provision. This was overcome by changing the NGO involved, replacing it with one that had a shared common understanding. Another interesting example for this type of barrier unfolded in the attempt to establish an innovative service network of public agencies and NGO's for homeless young citizens in Australia. Keast and Brown (2006) points out that the absence of a common purpose and goals between attending NGO's made the incorporation of partners in this network impossible.

A lack of trust is mentioned also as an interaction specific barrier between citizens and public agencies. Galli (2014) reports that a lack of trust between parents within a canteen committee and public administrations made the initiative to supply organic and locally sourced new school meals more difficult. This was because key decisions could not be taken in the conflicting climate. Finally, the evidence on citizen and NGO interaction barriers identified a lack of commitment by NGO`s (Jing and Gong 2012), inadequate accountability mechanisms (Maluka et al. 2011), unreliable and complex funding for NGO`s and union opposition (Borins 2000a), can all negatively impact upon the PSI process.

\section{Businesses as Suppliers}

Fourteen of the studies included within our review reported barriers relating to the interactions when private firms were supplying their resources to innovation process for profit. The most frequent barrier in this category was inadequate or failed contractors (Kumar, Maheshwari, and Kumar 2002; Bloch and Bugge 2013). For instance, in the case of a service innovation, Pelkonen (2015) reported that one of the contractors experienced economic troubles and failed to deliver. This was because the City of Helsinki did not establish within the contract a defined amount of service to be procured. Hence when demand was lower than expected the private partner was unable to make the service sufficiently profitable and the contractor failed. It is a noteworthy sign that the interaction specific barriers are shaped during the interaction. Moreover, it indicates process dynamics that we discuss later below. 
The second key barrier was tendering and contracting issues, which emerged as barriers when public procurement for innovation underwent difficulties such as "cost based contracting" (Hansson, Ovretveit, and Brommels 2012), "large and complex contracts" (Meijer 2015) or "assessment of new service concepts" in tendering evaluation (Pelkonen and Valovirta 2015). Lack of commitment (van Buuren, Eshuis, and Bressers 2015), ineffective network governance (Caloghirou, Protogerou, and Panagiotopoulos 2016) and a lack of shared understanding (Weber et al. 2014) were additional barriers mentioned between public organisationcontractor interactions.

\section{Politicians and Political Entities}

The distinction between public administration and politics is not clear-cut (Alford et al. 2016). PSI research recognises the central role of politicians (Hartley 2013). However, this is an understudied area, with no clear distinction as to where politicians stand during the innovation process: within the organisation or outside? In terms of barriers, Borins (2000b) makes a distinction between bureaucracy and politics, in which the latter is external. We preferred to analyse barriers related to politicians under the category of interaction specific ones, since they host dynamic relationships between public administration zone and political zone.

Barriers related to politicians were reported in eleven occasions within the reviewed studies. For example within one case, Helsinki City Hall ultimately did not approve funding for an innovation, which was an example of the lack of support from politicians (Bakici, Almirall, and Wareham 2013). Meijer (2015) reports that Citizen-Net police innovation faced political doubt by Member of Parliament as it was developed and scaled up. To sum up, our findings revealed that the barriers related to politicians and political entities need more investigation. This is consistent with the findings from others (e.g. Windrum and Koch 2008, Hartley 2014) who have demanded further studies on the role of politicians within the PSI.

\section{Businesses as Users or Co-Creators}

The private sector may involve itself within the PSI process in different ways other than supplying products or services for profit. First, they can act as the passive users of innovation. Competition and the negative effects of regulations on private sector interests can be barriers within this interaction (Borins 2000a; 2000b). On the other hand, governments may try to 
involve businesses to co-create innovations: Reaching target firms (Bakici, Almirall, and Wareham 2013), lack of commitment by the firms, and inadequate communication and knowledge sharing (Klievink, Bharosa, and Yao-Hua 2016) surfaced as interaction specific barriers in these cases.

\section{International Organisations}

Cooperation between the public sector and international organisations formed another potential source of barriers within the process, particularly within developing countries. A limited number of studies reported interaction specific barriers linked to international organisations, as they were funding innovations in Kenya, Lebanon and Poland. Project procedures, inadequate communication and knowledge sharing (Sabbat 1997), lack of shared understanding and finally delay of funding or end of funding (Abuya et al. 2010; Abuya et al. 2012) can be identified as barriers related to international organisations.

\section{iii. Innovation Characteristics Related Barriers}

In this part of our paper, we will explore innovation characteristics related barriers in the reviewed literature that are linked to the "perceived attributes of innovation" by adopters, which is rooted in Rogers' (2003) Diffusion of Innovations Theory. We found that the innovative solution itself was perceived as a barrier by the member of the organisation or by the target user group. Table 4 displays innovation specific barriers which was reported on fifty (17.73\%) occasions.

\section{Table 4: Innovation Characteristics as Barriers}

One of the most cited innovation characteristics specific barriers is incompatibility, which unfolds when an innovation is not "consistent with the existing values, past experiences and needs of potential adopters" (Rogers 2003, 240). If PSI is under discussion, the adopters and type of incompatibility varies. For instance, Brown's (2010) case of process innovation in social work, reports that it was "particularly challenging to fit the model into existing processes" (p. 8). This means the adopter was the organisation with all its processes; hence incompatibility with these processes forms a barrier. 
Complexity of an innovation was the other most cited barrier. Our evidence revealed that this type of difficulty surfaced predominantly as technical difficulties of a software or platform (De Civita and Dasgupta 2007; Costa, Arantes, and Valadares Tavares 2013; Ezzamel et al. 2014), however, in some rare cases it also related to complicated program procedures (Sabbat 1997). Additionally, switching costs, lack of interoperability, software or platform problems, inflexibility can impede innovation process as barriers related to characteristics of concrete innovation.

\section{iv. Contextual Barriers}

Finally, there were thirty-three (12 per cent) occasions where coded barriers can be linked to context. Table 5 shows that current laws, regulations and policies were the dominant contextual barrier that the innovators faced during the process: Restrictive tendering regulations (Pelkonen and Valovirta 2015) were frequent examples of this. The study of (Klievink, Bharosa, and Yao-Hua 2016) explored a public-private business reporting platform in the Netherlands where innovators faced the restrictive regulatory aspect, as the platform could not be owned by private companies or trade chambers. Further, in the case of Citizens' Initiative by European Parliament, (Susha and Gronlund 2014) found out that the innovation regulatory framework within the EU made the innovation too costly for the organisers when developing a signature petition for the security of digital citizen data. These examples show that laws and regulations can affect the innovation process in various ways.

\section{Table 5: Contextual Barriers}

On the other hand, the lack of standardisation can also surface as a barrier within the innovation process, particularly in the case of IT or e-government innovations. A notable example of this is in four EU countries, where custom agencies lacked a standardized procedural template for e-customs innovation (Raus, Fluegge, and Boutellier 2009). An excessive number of e-platforms for e-procurement were a converse example of the lack of standardisation within public e-procurement innovation in Portugal (Costa, Arantes, and Valadares Tavares 2013).

\section{B. PROCESS STAGES AND BARRIERS}


This section examines how the characters of barriers differ between the key stages of the innovation process. The barriers to innovation may vary according to the phases of the innovation process (Hadjimanolis 2003; Sandberg and Aarikka-Stenroos 2014). We employed four stages to observe the patterns of barriers during the innovation process, whilst acknowledging its "iterative, complex, multi-directional" and "non-linear" nature (Walker, Jeanes, and Rowlands 2001; Torugsa and Arundel 2016). Many prior researchers have adopted such a stage based method as an analytical tool (e.g. Sandberg and Aarikka-Stenroos 2014; De Vries, Bekkers, and Tummers 2016, Meijer 2014). Similarly, we construct from the literature a set of four observation stages: idea generation (Hartley, Sørensen, and Torfing 2013), development and design (Osborne 2002), implementation (Osborne 2002; Walker, Jeanes, and Rowlands 2001), and finally sustainment (Stirman et al. 2012). This approach enables us to shed light on the difficulties of particular activities within the innovation process.

A total of two hundred and thirty five barriers (see Table 6) identified could be assigned to a stage of the process. Some articles did not distinctly identify the stages of process and instead focused on factors. However, the authors were able to identify to which stage they referred with relative ease. It might be argued that this coding was subjective, however, mapping the barriers can enable us understanding the process characteristics of barriers.

\section{Table 6: Process Stages and Barriers}

\section{Idea Generation and Selection}

Idea generation and selection related to activities involved following the identification of a problem or need to innovate. In this stage the organisation attempts to invent or match an innovation somewhere else to a perceived and recognised problem (Rogers 2003). We find that the challenges that the innovators face while they are trying to find the right solutions are studied relatively rarely in only thirteen articles. These barriers, mentioned in twentythree occasions, accounted for 10 per cent of total mapped barriers.

The study of Marsden (2011) provided particular insights; specifically investigating the idea generation phase in the case of transport innovations within ten cities across eight countries. This study revealed that a lack of available and accessible information on innovations 
elsewhere, an unsystematic search, high levels of risk aversion, a lack of resources and a lack of an organisational learning culture acted as barriers to public organisations.

\section{Development and Design}

Within the second phase of the process, development and design, the idea is crafted in order to fit the purpose of serving the public better. Rogers (2003) describes this step where the activities to "restructure and modify innovation" occur, whilst Bason (2010) labelled it as "prototyping". In a similar way, Roberts and Longley (2013) define it as "initiation is followed by the design phase that translates the idea into a more concrete and tangible form".

Barriers relating to the development and design phase were mentioned in a total of seventy occasions, and thus accounted for 30 per cent of total mapped barriers. The nature of PSI, which typically involves a wide range of areas and influences many interest groups; and results in this phase requiring discussions in policy areas and policy networks (van Buuren and Loorbach 2009; Susha and Gronlund 2014).

A study by Biesbroek et.al (2014) investigated how an innovative water management solution, a water plaza, in Rotterdam, faced barriers during development and design phase. High levels of aversion to risk, inappropriate framing and prior conflicts impeded the innovation, triggering other barriers in the form of public doubt and conflict between public organisations.

Van Buuren, Eshuis, and Bressers (2015) explored the compatibility of three innovative water management initiatives to the established values of water management policy area in the Netherlands. Their findings indicated that the innovation`s incompatibility to organisational values "dominant values in Dutch water governance" was the main barrier to innovation process. It is worth noting that values negatively influencing innovation, reinforced with incompatibility, which formed a barrier to innovation. We will discuss this relationship and underlying mechanisms of barriers in the next section.

One further study warrants discussion within this section. Caloghirou`s (2016) study analysed the attempt to develop a standardised electronic service scheme within Greek municipalities: one main contractor and several sub-contractors were responsible to develop the platform for eight municipalities. In this case, ineffective governance of this network, along with lack 
of commitment by local governments, surfaced as interaction specific barriers and caused delays in the process. Another barrier worth noting related to maintaining the interconnection of electronic services across government. This lack of interoperability in platform design resulted in an unwillingness of municipalities to adopt the innovation.

\section{Implementation}

We view implementation as the phase when organisation(s) put innovation into action. Barriers within this phase were reported in one hundred and twenty eight occasions indicating this phase contained the greatest number of barriers (55\%).

Piening`s (2011) work focuses on the implementation process and its management where he compares a successful and failed implementation of an incremental innovation in German public hospitals reports solely organisational barriers. Rigid organisational structure, topdown approach, lack of human resources, time pressure, lack of knowledge, power struggles in innovation along with staff resistance made the process more difficult and even resulted in failure in these cases.

On the other hand, we find articles that explored the implementation of very large policy innovations. For instance, Landry, Lemak and Hall (2011) studied the innovative Medicaid program in Florida. Although the program underwent a successful implementation, they reported barriers in all categories. As many stakeholders were included in the stage, the new program suffered from lack of shared understanding in terms of goal consensus. In addition, ineffective governance of health provider networks also surfaced as interaction specific barrier. Similarly, Abuya et al. (2012) reports that an extensive health policy innovation in Kenya experienced interaction specific barriers where inadequate contractors with low commitment slowed down the innovation.

\section{Sustainment}

The final stage we examined, after the launch, involved the sustainment of the innovation and its ability to become routine within the organisation (Rogers 2003; Stirman et al. 2012). We find only twelve studies reporting barriers on the sustainment period, and these barriers account for only $6 \%$ of mapped barriers. 
The primary barrier to the routinization of innovations was related to financial resources. This was particularly apparent in cases involving subsidies or international aid projects, where after a predefined time the funding comes to an end. The only study exploring this phase in depth was in the Netherlands. Cramer, Dewulf, and Voordijk (2014) investigated 26 subsidised projects by ministries for health innovations. The ending of funding after three years hindered each of these innovative projects. Moreover, the program lacked commitment and shared understanding from both the ministry and health organisations. Many conflicts and resistance about the duration of subsidies existed in the ministry. In addition, health organisations focused on subsidies instead of content of the innovation and tried mainly to win the subsidy.

Transitions occurring within the process also impeded the sustainment period. For example, political transition in Baltimore city or managerial transitions in New York City Juvenile Justice Department were examples of these barriers (Sanger 2008; Schall 1997).

At the end of this section, we analyse whether some phases of process are more related to specific types of barriers. Table 7 summarises the frequency of each category of barriers mentioned within each stage of the process.

Table 7: Barriers Mapped to Process Stages

First, we notice that organisational barriers play the largest role in hindering all process stages. It is coherent with our preliminary results that organisational barriers are the most frequently mentioned type in reviewed articles. Second, our analysis reveals that interaction specific barriers were the most influential in sustainment stage. The reason for it is that organisations needed support from collaborators in terms of resources to sustain innovations. A lack of support plays a significant role in impeding long term initiatives. The final key finding relating to stages is the influence of organisational barriers decreases as the process progresses, whilst interaction barriers increase. We suggest this may be due to the fact that as an innovation evolves across the stages it experiences more collective action, and may be more heavily influenced by these interactions.

\section{INTERRELATIONS BETWEEN BARRIERS}


In this section of the review findings, we analyse the dynamic nature between the barriers. Hadjimanolis (2003), who attempted to construct a barrier approach to innovation, identified that the characteristics of barriers is dynamic rather than static. He pointed out that they evolve and are interrelated within the innovation process. The investigation is for underlying mechanisms, as Hadjimanolis (2003) emphasized: 'Barriers-especially internal ones-may emerge as symptoms, and their deeper causes and underlying factors have to be accounted for'. In addition, Termeer (2009) concluded 'barriers cannot be viewed as isolated obstacles to horizontal modes of governance because they reinforce each other'. Hence this section aims to highlight the evidence for such interrelations.

Forty three text fragments (15\%) coded in our review provided insights into the relationships or underlying mechanisms between barriers. The investigation of dynamic phenomenon requires in depth analysis, reflecting that each of the studies providing these dynamic insights were methodologically qualitative. However, most of the articles only reported the interrelationship between barriers in an illustrative manner. Where these relationships were detailed they were coded by the authors. This is exemplified in the work undertaken by Abuya et al. (2012), Gardner et al (2010) and, Keast and Brown (2006) where they report the barriers whilst detailing the story of an innovation case study.

Our review uncovered a few good examples of papers focusing on underlying mechanisms of barriers. This can be clearly seen in the case of the water plaza innovation in Rotterdam in which the authors looked for "mechanism-based explanation of impasses". Biesbroek et al. (2014) identified three: i. Ongoing bad relationships between local governments lead to lack of shared understanding for the innovation collaboration. ii. High risk aversion resulted in public opposition and conflicts with sub-municipality. iii. Inappropriate framing contributed to public opposition. Another example of papers signifying underlying mechanisms is by Azad and Faraj (2011) in which they explored the power struggles and their explanations in the case of IT innovation in Lebanon. They identified power struggles co-evolving with the resistance of staff. Manager resistance was another barrier identified, where members of organisation were trying to frame the meaning of activities and content of innovation in order to preserve their current power position and rent seeking behaviour. 
Nearly half of the evidence revealed the origins of resistance or lack of support resulted from within organisation. These included: High risk aversion, rent seeking culture, increasing workload due to innovation, power struggles, lack of knowledge about innovation, unclear responsibilities, complexity of innovation are reported as barriers which acted the sources of restrictive behaviour among organisational members. Furthermore, the underlying reasons of citizen related difficulties are reported in 20 occasions (47 per cent). Whilst lack of mutual benefits, laws and regulations, network structure, lack of resources, lack of trust and high risk aversion were significant barriers within the process, they also resulted in lack of commitment to working together to innovate. Thus we argue that the identification of underlying barriers is crucial to understand and overcome the resistance and opposition against innovation.

With the aim of a further analysis, we investigated the dynamic relationship of process stages in terms of barriers. We found 11 occasions that reported one difficulty in a previous stage can trigger another barrier in a later stage. These interrelations are predominantly between development and implementation phases which accounted for $85 \%$ of all occasions. Topdown approach and inadequate involvement of staff in the discussions within the design and development stage lead to staff resistance in the case of organisational innovation in Brazilian hospital (Bernardes et al. 2012). Another example is that the innovation attempts to establish a network of public and third sector organisations suffered from a lack of commitment by members in the implementation phase, as they were not able to establish a shared understanding in the development phase (Keast and Brown 2006).

Our analysis of the findings demonstrates the importance of development phase within the process. Barriers in the development and design phase can lead to new barriers or become more severe barriers itself acting like a snowball.

\section{BARRIERS AND TYPE OF INNOVATIONS}

In this final section we explore whether the innovation barriers show different characteristics in terms of ICT and non-technological innovations. Prior research has revealed that innovation barriers may reveal distinctive contingencies according to the type of innovation (Hadjimanolis 2003; Torugsa and Arundel 2016). In order to investigate this, we distinguished ICT innovations and non-technological innovations such as policy, social and administrative process innovations (see Table 8). Our analysis revealed that organisational and innovation 
characteristics related barriers were relatively more influential for ICT innovations (e.g. Costa 2013). On the other hand interaction-specific barriers emerged as the major challenge for non-technological innovations (examples are Termeer 2009; van Buuren 2015). The reason for this may be that non-technological innovations are more open and involve more and varied types of actors than ICT innovations.

Table 8 Innovation Types and Barriers

\section{CONCLUSIONS}

The purpose of this systematic review was to examine the nature of barriers within the PSI process. In doing so, our goal was to integrate the fragmented academic knowledge produced by pertinent studies. Moreover, the paper offered a research avenue to enhance our understanding of barriers further.

\section{Figure 3 Framework of the nature of barriers}

In order to gain a clear empirical understanding of the literature on barriers to PSI process we conducted a systematic review which addressed the following research questions: What are the specific barriers within the PSI process and how can these be classified? How do the barriers within the process differ between the key stages of the innovation process? What is the interrelation between the various barriers within the innovation process? How do the barriers within the process differ between technological and non-technological innovations? Our findings show that barriers have more than one dimension and thus they are more complex and dynamic than have hitherto been reported. Figure 3 presents the four dimensions of barriers we have investigated, and link these to the more well-known previously identified barriers.

First, regarding to their types, the most reported barriers are organisation related. In particular the administration of process is the most significant barrier in this category. This may be due to the New Public Management approach to study innovation, which focuses on the organisation and managers as the unit of analysis. Interaction barriers are the second 
most influential. Public sector organisations build relationships with other institutions and citizens to try to deliver innovation successfully. Nonetheless, and unsurprisingly these collaborative processes host many difficulties. The third specific barrier we identified is related to the content of innovation, which has been discussed by Rogers (2003) as 'perceived characteristics of innovation`.

On the other hand, our subsequent research questions revealed that the nature of barriers are beyond this static classification and seem more complex than has previously been recognized.

In addressing our second research question we adopted a process approach which led us to uncover that barriers show different features across phases of the innovation process: The implementation phase experiences the highest number of barriers. This is followed by development \& design of innovation, idea generation and sustainment phases. Finally, our study found that the influence of interaction barriers have increased across stages, while the number of stakeholders are growing.

In analysing our third research question we found that there can be a dynamic relationship between barriers. We find barriers can interrelate and may emerge as symptoms of other. Moreover, failures at one point of the process can lead to more serious difficulties at later stages. Significantly, this has not been widely studied within the literature.

Lastly, the fourth research question revealed that barriers show different characteristics between distinct innovation types. Whilst organisational and innovation characteristics' related barriers were relatively more influential for ICT innovations, interaction-specific barriers emerged as the major challenge for non-technological innovations.

This paper gives an insight to public sector managers into the difficulties they may face within the entire innovation process. First, there is a need to recognize that the administration of innovation activities has a crucial influence on its success and an ineffective process management may hamper the novel initiative. They should also understand that the resistance by organisational members is a natural part of the innovation process, and they need to be prepared to take actions to win the hearts of inside opposition. Secondly, PSI ought to be viewed entirely as a collaborative process that enhances their initiatives. Specifically, 
they should choose their partners very carefully and lay explicitly the groundwork for collaboration as they are building partnerships with diverse organisations and citizen groups. Third, the content of innovation should be considered and cautiously designed in accordance with the needs of organisations and citizens. Fourth, the variation of barriers differs between innovation types. They need to focus on organisational difficulties and design challenges in case of ICT innovations, whereas social and administrative process innovations require an emphasis on collaborators. Finally, they should try to recognize and overcome problems as soon as possible because they may evolve into more serious barriers during the process. This study can assist them in becoming more aware of potential barriers, and thus adopt a proactive approach in order to overcome these complex barriers.

These conclusions bring us also to a future research agenda around barriers to PSI. First we propose that the future research avenue on PSI should explore all aspects of barriers; specifically the interrelations between barriers. Second, research should focus on the nature of interaction barriers due to the increasing levels of stakeholders attempting to build collaborations to innovate. This means the unit of analysis should turn to systems and networks rather than one organisation. In particular, interaction specific barriers with businesses and political entities need further investigation. Studies on barriers should also examine particular phases of the process. In general, barriers within the idea generation and selection, design and development, and sustainment stages have not been studied in detail and need further investigation. Further, there is an absence of cross-national studies. Third, it is worthy of note that most of the articles in our review were qualitative in nature. Hence, there is a need for quantitative studies with large samples which facilitate generalisability. Finally, some scholars suggest that barriers can be regarded as opportunities to design and modify the innovation so that it becomes more appropriate to the particular context (Borins 2014). There is a lack of research studying this aspect of barriers. The only pertinent finding relevant to this, within our reviewed articles, was Torugsa and Arundel (2016), who identified that barriers did not negatively affect beneficial outputs of an innovation. Further research could broaden the horizon of the conventional view on innovation barriers by investigating the relationship between barriers and long term innovation survival. 
This study offers the first detailed review of barriers to PSI. This research has shown that the nature of barriers are complicated and not well understood, although there has been a general perception that the barriers to PSI are well studied (e.g. Brown 2015).

\section{LIMITATIONS}

Our study has its limitations. First, it is important to recognize the limitation of searched terms. PSI might be studied with other terminologies such as change, New Public Management, IT implementation etc. However, including each of these terms would have increased the number of studies significantly beyond the existing 3,950 articles. Thus, our search terms are restricted to innovation and entrepreneurship. Second, we utilised $\mathrm{SSCl}$ and EBSCO databases. Although they are reasonably comprehensive, some studies may have been omitted. Third, we focused on only barriers and difficulties. Studying barriers with tactics that are used to overcome them might shed new insights on the nature of barriers. However, such an inclusion would exceed the scope of a single journal paper. Finally, as we have emphasized, the literature has focused mainly on western countries. This forced our study to be context dependent. We acknowledge that PSI within other country contexts may pose different barriers. Despite these limitations, this paper provides a means to better understand the complex nature of innovation barriers within public sector for both researchers and practitioners.

\section{ACKNOWLEDGEMENT}

We would like to thank a number of PSI scholars for their contribution to identify relevant studies: Prof. Sandford Borins of the University of Toronto; Prof. Stephen Osborne of the University of Edinburgh, Prof. Richard Walker of the City University of Hong Kong.

\section{REFERENCES}

\section{*Included in systematic review}

*Aagaard, P. 2012. "Drivers and Barriers of Public Innovation in Crime Prevention." Innovation Journal 17 (1): 2-17.

*Abuya, T, A. Amin, S. Molyneux, W. Akhwale, V. Marsh, and L. Gilson. 2010. "Importance of Strategic Management in the Implementation of Private Medicine Retailer Programmes: Case 
Studies from Three Districts in Kenya." BMC Health Services Research 10 (1). doi:10.1186/1472-6963-10-S1-S7.

*Abuya, T., R. Njuki, C. E. Warren, J. Okal, F. Obare, L. Kanya, I. Askew, and B. Bellows. 2012. "A Policy Analysis of the Implementation of a Reproductive Health Vouchers Program in Kenya." BMC Public Health 12 (July). doi:10.1186/1471-2458-12-540.

Alford, J., J. Hartley, S. Yates, and O. Hughes. 2016. "Into the Purple Zone." The American Review of Public Administration, March. SAGE Publications, 275074016638481. doi:10.1177/0275074016638481.

Ansell, C., and A. Gash. 2008. "Collaborative Governance in Theory and Practice." Journal of Public Administration Research and Theory: J-PART VO - 18, no. 4. Oxford University Press: 543. doi:10.1093/jopart/mum032.

Arundel, A., L. Casali, and H. Hollanders. "How European public sector agencies innovate: The use of bottom-up, policy-dependent and knowledge-scanning innovation methods." Research Policy 44, no. 7 (2015): 1271-1282.

*Azad, B., and S. Faraj. 2011. "Social Power and Information Technology Implementation: A Contentious Framing Lens." Information Systems Journal 21 (1): 33-61. doi:10.1111/j.13652575.2010.00349.x.

*Bakici, T., E. Almirall, and J. Wareham. 2013. "The Role of Public Open Innovation Intermediaries in Local Government and the Public Sector." Technology Analysis \& Strategic Management 25 (3, SI): 311-327. doi:10.1080/09537325.2013.764983.

*Bartlett, D., and P. Dibben. 2002. "Public Sector Innovation and Entrepreneurship: Case Studies from Local Government." Local Government Studies 28 (4): 107-121. doi:10.1080/714004159.

Bason, C. 2010. Leading Public Sector Innovation: Co-Creating for a Better Society. Policy Press. 
*Bazemore, A., R. L. Phillips, and T. Miyoshi. 2010. "Harnessing Geographic Information Systems (GIS) to Enable Community-Oriented Primary Care." Journal Of The American Board Of Family Medicine 23 (1): 22-31. doi:10.3122/jabfm.2010.01.090097.

*Bernardes, A., G. Cummings, Y. D. M. Evora, and C. S. Gabriel. 2012. "Framing the Difficulties Resulting from Implementing a Participatory Management Model in a Public Hospital." Revista Latino-Americana De Enfermagem 20 (6): 1142-1151.

*Biesbroek, G. R., C. J. A. M. Termeer, J. E. M. Klostermann, and P. Kabat. 2014. “Rethinking Barriers to Adaptation: Mechanism-Based Explanation of Impasses in the Governance of an Innovative Adaptation Measure." Global Environmental Change 26 (1). Elsevier Ltd: 108-118. doi:10.1016/j.gloenvcha.2014.04.004.

Blanchard, P., J. Huiban, A. Musolesi, and P. Sevestre. "Where there is a will, there is a way? Assessing the impact of obstacles to innovation." Industrial and Corporate Change 22, no. 3 (2012): 679-710.

*Bloch, C., and M. M. Bugge. 2013. "Public Sector Innovation-From Theory to Measurement." Structural Change and Economic Dynamics 27 (SI): 133-145. doi:10.1016/j.strueco.2013.06.008.

Bommert, B. 2010. "Collaborative Innovation in the Public Sector." International Public Management Review 11 (1): 15-33.

Borins, S. F. 1998. Innovating with Integrity: How Local Heroes Are Transforming American Government. Washington, DC: Georgetown University Press.

*Borins, S.F. 2000a. "What Border? Public Management Innovation in the United States and Canada." Journal of Policy Analysis and Management 19 (1): 46-74. doi:10.1002/(SICI)15206688(200024)19:1<46::AID-PAM4>3.0.CO;2-Z.

*Borins, S.F. 2000b. "Loose Cannons and Rule Breakers, or Enterprising Leaders? Some Evidence about Innovative Public Managers." Public Administration Review 60 (6): 498-507. doi:10.1111/0033-3352.00113. 
Borins, S. F. 2014. The Persistence of Innovation in Government. Innovative Governance in the 21st Century: Volume 8. Washington, District of Columbia : Brookings Institution Press.

*Brown, L. 2010. "Balancing Risk and Innovation to Improve Social Work Practice." British Journal of Social Work 40 (4, SI): 1211-1228. doi:10.1093/bjsw/bcq013.

Brown, L., and S. P Osborne. 2013. "Risk and Innovation: Towards a Framework for Risk Governance in Public Services." Public Management Review 15 (2, SI): 186-208. doi:10.1080/14719037.2012.707681.

Brown, L. 2015. "A lasting legacy? Sustaining innovation in a social work context." British Journal of Social Work 45, no. 1: 138-152.

*Caloghirou, Y., A. Protogerou, and P. Panagiotopoulos. 2016. "Public Procurement for Innovation: A Novel eGovernment Services Scheme in Greek Local Authorities." Technological Forecasting And Social Change 103 (February): 1-10. doi:10.1016/j.techfore.2015.10.016.

*Costa, A. A., A. Arantes, and L. V. Tavares. 2013. "Evidence of the Impacts of Public EProcurement: The Portuguese Experience." Journal of Purchasing and Supply Management 19 (4). Elsevier: 238-246. doi:10.1016/j.pursup.2013.07.004.

*Cramer, H., G. Dewulf, and H. Voordijk. 2014. "The Barriers to Govern Long-Term Care Innovations: The Paradoxical Role of Subsidies in a Transition Program." Health Policy 116 (1): 71-83. doi:10.1016/j.healthpol.2014.02.008.

D’Este, P., S. lammarino, M. Savona, and N. von Tunzelmann. 2012. "What Hampers Innovation? Revealed Barriers versus Deterring Barriers." Research Policy 41 (2): 482-488. doi:10.1016/j.respol.2011.09.008.

*De Civita, M., and K. Dasgupta. 2007. "Using Diffusion of Innovations Theory to Guide Diabetes Management Program Development: An Illustrative Example." Journal Of Public Health 29 (3): 263-268. doi:10.1093/pubmed/fdm033.

De Vries, H., V. Bekkers, and L. Tummers. 2016. "Innovation in the Public Sector: A Systematic Review and Future Research Agenda." Public Administration 94 (1): 146-166. doi:10.1111/padm.12209. 
*Dorado, S., and P. Vaz. 2003. "Conveners as Champions of Collaboration in the Public Sector: A Case from South Africa." Public Administration and Development 23 (2): 141-150. doi:10.1002/pad.270.

*Ezzamel, M., N. Hyndman, A. Johnsen, and I. Lapsley. 2014. “Reforming Central Government: An Evaluation of an Accounting Innovation." Critical Perspectives on Accounting 25 (4-5): 409-422. doi:10.1016/j.cpa.2013.05.006.

Galia, F., and D. Legros. "Complementarities between obstacles to innovation: evidence from France." Research Policy 33, no. 8 (2004): 1185-1199.

Galia, F., S. Mancini, and V. Morandi. "Obstacles to innovation: what hampers innovation in France and Italy?." DRUID Society (2012).

*Galli, F., G. Brunori, F. Di lacovo, and S. Innocenti. 2014. "Co-Producing Sustainability: Involving Parents and Civil Society in the Governance of School Meal Services. A Case Study from Pisa, Italy." Sustainability 6 (4): 1643-1666. doi:10.3390/su6041643.

*Gardner, K. L, M. Dowden, S. Togni, and R. Bailie. 2010. "Understanding Uptake of Continuous Quality Improvement in Indigenous Primary Health Care: Lessons from a MultiSite Case Study of the Audit and Best Practice for Chronic Disease Project." Implementation Science 5 (March). doi:10.1186/1748-5908-5-21.

*Gil-Garcia, J. R., I. Chengalur-Smith, and P. Duchessi. 2007. "Collaborative E-Government: Impediments and Benefits of Information-Sharing Projects in the Public Sector." European Journal of Information Systems 16 (2): 121-133. doi:10.1057/palgrave.ejis.3000673.

Greenhalgh, T., G. Robert, F. Macfarlane, P. Bate, and O. Kyriakidou. 2004. "Diffusion of Innovations in Service Organizations: Systematic Review and Recommendations." Milbank Quarterly 82 (4). Wiley Online Library: 581-629.

Hadjimanolis, A. 2003. "The Barriers Approach to Innovation." In The International Handbook on Innovation, edited by L. V. Shavinina, 559-573. doi:10.1016/B978-008044198-6/50038-3.

*Hansson, J., J. Ovretveit, and M. Brommels. 2012. "Case Study of How Successful Coordination Was Achieved between a Mental Health and Social Care Service in Sweden." 
International Journal of Health Planning and Management 27 (2): e132-e145. doi:10.1002/hpm.1099.

Hartley, J. 2013. "Public and Private Features of Innovation." In Handbook of Innovation in Public Services, edited by Osborne, S.P.; L. Brown, 44-59. Cheltenham, UK: Edward Elgar Publishing.

Hartley, J. 2014. "New Development: Eight and a Half Propositions to Stimulate Frugal Innovation." Public Money \& Management 34 (3). Routledge: 227-32. doi:10.1080/09540962.2014.908034.

Hartley, J., E. Sørensen, and J. Torfing. 2013. "Collaborative Innovation: A Viable Alternative to Market Competition and Organizational Entrepreneurship." Public Administration Review 73 (6): 821-830. doi:10.1111/puar.12136.

*Henning, F., and G. Y. NG. 2009. "The Challenge of Collaboration - Ict Implementation Networks in Courts in the Netherlands." Transylvanian Review of Administrative Sciences, no. 28E, SI: $27-44$.

*Jing, Y, and T. Gong. 2012. "Managed Social Innovation: The Case of Government-Sponsored Venture Philanthropy in Shanghai." Australian Journal of Public Administration 71 (2): 233245. doi:10.1111/j.1467-8500.2012.00767.x.

*Keast, R., and K. Brown. 2006. "Adjusting to New Ways of Working: Experiments with Service Delivery in the Public Sector." Australian Journal of Public Administration 65 (4): 41-53. doi:10.1111/j.1467-8500.2006.00503a.x.

Kickert, W. J. M. 1997. "Public Governance in the Netherlands: An Alternative To AngloAmerican 'Managerialism.'” Public Administration 75 (4): 731-752. doi:10.1111/14679299.00084.

*Klievink, B., N. Bharosa, and T. Yao-Hua. 2016. "The Collaborative Realization of Public Values and Business Goals: Governance and Infrastructure of Public-Private Information Platforms." Government Information Quarterly 33 (1): 67-79. doi:10.1016/j.giq.2015.12.002. 
*Kraemer, S. R. Johnsdatter, L. T. Nikolajsen, and G. Gulis. 2014. "Implementation of Health Impact Assessment in Danish Municipal Context." Central European Journal of Public Health 22 (4): 211-214.

*Kumar, V., B. Maheshwari, and U. Kumar. 2002. "ERP Systems Implementation: Best Practices in Canadian Government Organizations." GOVERNMENT INFORMATION QUARTERLY 19 (2): 147-172. doi:10.1016/S0740-624X(02)00092-8.

*Landry, A. Y., C. H. Lemak, and A. Hall. 2011. "Successful Implementation in the Public Sector: Lessons Learned from Florida's Medicaid Reform Program." Journal of Public Health Management and Practice 17 (2): 154-163. doi:10.1097/PHH.0b013e3181f54154.

*Levine, J. R., and W. J. Wilson. 2013. "Poverty, Politics, and a "Circle of Promise: Holistic Education Policy in Boston and the Challenge of Institutional Entrenchment." Journal of Urban Affairs 35 (1): 7-24. doi:10.1111/juaf.12001.

*Maluka, S., P. Kamuzora, M. SanSebastian, J. Byskov, B. Ndawi, O. E. Olsen, and A. Hurtig. 2011. "Implementing Accountability for Reasonableness Framework at District Level in Tanzania: A Realist Evaluation." Implementation Science 6 (February). doi:10.1186/17485908-6-11.

*Marsden, G., K. T. Frick, A. D. May, and E. Deakin. 2011. "How Do Cities Approach Policy Innovation and Policy Learning? A Study of 30 Policies in Northern Europe and North America." Transport Policy 18 (3, SI): 501-512. doi:10.1016/j.tranpol.2010.10.006.

*Martin, G. P., G. Currie, and R. Finn. 2009. "Leadership, Service Reform, and Public-Service Networks: The Case of Cancer-Genetics Pilots in the English NHS." Journal of Public Administration Research and Theory 19 (4): 769-794. doi:10.1093/jopart/mun016.

Meijer, A. 2014. "From Hero-Innovators to Distributed Heroism: An in-Depth Analysis of the Role of Individuals in Public Sector Innovation." Public Management Review 16 (2). Routledge: 199-216. doi:10.1080/14719037.2013.806575.

*Meijer, A. 2015. "E-Governance Innovation: Barriers and Strategies." Government Information Quarterly 32 (2). Elsevier Inc.: 198-206. doi:10.1016/j.giq.2015.01.001. 
Moher, D., A. Liberati, J. Tetzlaff, and D. G. Altman. 2009. "Preferred Reporting Items for Systematic Reviews and Meta-Analyses: The PRISMA Statement." PLoS Medicine 6 (7). Public Library of Science: 1-6. http://10.0.5.91/journal.pmed.1000097.

*Nedovic-Budic, Z., and D. R. Godschalk. 1996. "Human Factors in Adoption of Geographic Information Systems: A Local Government Case Study." Public Administration Review 56 (6): 554-567.

OECD (2008), OECD Glossary of Statistical Terms, OECD Publishing, Paris. DOI: http://dx.doi.org/10.1787/9789264055087-en

Osborne, S. P. 2002. Voluntary Organizations and Innovation in Public Services. [Electronic Resource]. Routledge Studies in the Management of Voluntary and Non-Profit Organizations: 1. London; New York : Routledge.

Osborne, S. P. 2006. “The New Public Governance?" Public Management Review 8 (3): 377388. doi:10.1080/14719030600853022.

Osborne, S. P, and L. Brown. 2011. "Innovation, Public Policy and Public Services Delivery in the Uk. The Word That Would Be King?" Public Administration 89 (4): 1335-1350. doi:10.1111/j.1467-9299.2011.01932.x.

*Ovseiko, P. V., C. O'Sullivan, S. C. Powell, S. M. Davies, and A. M. Buchan. 2014. "Implementation of Collaborative Governance in Cross-Sector Innovation and Education Networks: Evidence from the National Health Service in England." BMC Health Services Research 14 (November). doi:10.1186/s12913-014-0552-y.

Pärna, O., and N. von Tunzelmann. "Innovation in the public sector: Key features influencing the development and implementation of technologically innovative public sector services in the UK, Denmark, Finland and Estonia." Information Polity 12, no. 3 (2007): 109-125.

*Pelkonen, A., and V. Valovirta. 2015. "Can Service Innovations Be Procured? An Analysis of Impacts and Challenges in the Procurement of Innovation in Social Services." Innovation-The European Journal of Social Science Research 28 (3, SI): 384-402. doi:10.1080/13511610.2014.999026. 
*Piening, E. P. 2011. "Insights into the Process Dynamics of Innovation Implementation." Public Management Review 13 (1): 127-157. doi:10.1080/14719037.2010.501615.

*Pietroburgo, J. 2012. "Saving Fido: A Case in the Privatization of Local Animal Control Services." Innovation Journal 17 (2): 1-12.

*Plotnikof, M. 2015. "Negotiating Collaborative Governance Designs: A Discursive Approach." Innovation Journal 20 (3): 1-22.

*Raus, M., B. Fluegge, and R. Boutellier. 2009. "Electronic Customs Innovation: An Improvement of Governmental Infrastructures." Government Information Quarterly 26 (2): 246-256. doi:10.1016/j.giq.2008.11.008.

Roberts, N. C., and P. J. King. 1996. Transforming public policy: Dynamics of policy entrepreneurship and innovation. Jossey-Bass Incorporated Pub.

Roberts, N. C., and C. Longley. 2013. “12. Against All Odds: Bottom-up Entrepreneurship and Innovation in the Department of Defense." In Handbook of Innovation in Public Services, edited by Osborne, S.P.; L. Brown, 176-192. Cheltenham, UK: Edward Elgar Publishing.

*Rocque, M., B. C. Welsh, P. W. Greenwood, and E. King. 2014. "Implementing and Sustaining Evidence-Based Practice in Juvenile Justice: A Case Study of a Rural State." International Journal of Offender Therapy and Comparative Criminology 58 (9): 1033-1057. doi:10.1177/0306624X13490661.

Rogers, E. M. 2003. Diffusion of Innovations. London : Simon \& Schuster.

*Sabbat, J. 1997. "International Assistance and Health Care Reform in Poland: Barriers to Project Development and Implementation." Health Policy 41 (3): 207-227. doi:10.1016/S0168-8510(97)00034-1.

Sandberg, B., and L. Aarikka-Stenroos. 2014. "What Makes It so Difficult? A Systematic Review on Barriers to Radical Innovation." Industrial Marketing Management 43 (8). Elsevier Inc.: 1293-1305. doi:10.1016/j.indmarman.2014.08.003.

*Sanger, M. B. 2008. "From Measurement to Management: Breaking through the Barriers to State and Local Performance." Public Administration Review 68 (S): S70-S85. 
*Schall, E. 1997. "Public-Sector Succession: A Strategic Approach to Sustaining Innovation." Public Administration Review 57 (1): 4-10. doi:10.2307/976686.

Sørensen, E., and J. Torfing. 2011. "Enhancing Collaborative Innovation in the Public Sector." Administration \& Society 43 (8): 842-868. doi:10.1177/0095399711418768.

Sørensen, E., and J. Torfing. 2016. "Collaborative Innovation in the Public Sector." In Enhancing Public Innovation by Transforming Public Governance, edited by Jacob Torfing and Peter Triantafillou, 115-116. Cambridge: Cambridge University Press. doi:DOI: 10.1017/CBO9781316105337.006.

Stirman, S.W., J. Kimberly, N. Cook, A. Calloway, F. Castro, and M. Charns. 2012. "The Sustainability of New Programs and Innovations: A Review of the Empirical Literature and Recommendations for Future Research." Implement Sci 7 (1): 17. doi:10.1186/1748-5908-717.

*Susha, I., and A. Gronlund. 2014. "Context Clues for the Stall of the Citizens' Initiative: Lessons for Opening up E-Participation Development Practice." Government Information Quarterly 31 (3): 454-465. doi:10.1016/j.giq.2014.02.005.

*Termeer, C. J. A. M. 2009. "Barriers to New Modes of Horizontal Governance." Public Management Review 11 (3): 299-316. doi:10.1080/14719030902798180.

*Torugsa, N. (A.), and A. Arundel. 2016. "Complexity of Innovation in the Public Sector:A Workgroup-Level Analysis of Related Factors and Outcomes." Public Management Review 18 (3): 392-416. doi:10.1080/14719037.2014.984626.

Tummers, L. L. G, V.Bekkers, E. Vink, and M. Musheno. 2015. “Coping during Public Service Delivery: A Conceptualization and Systematic Review of the Literature." Journal of Public Administration Research and Theory 25 (4): 1099-1126. doi:10.1093/jopart/muu056.

*Van Buuren, A., J. Eshuis, and N. Bressers. 2015. "The Governance of Innovation in Dutch Regional Water Management: Organizing Fit between Organizational Values and Innovative Concepts." Public Management Review 17 (5): 679-697. doi:10.1080/14719037.2013.841457. 
*Van Buuren, A., and D. Loorbach. 2009. "Policy Innovation in Isolation?" Public Management Review 11 (3): 375-392. doi:10.1080/14719030902798289.

Van de Ven, A. H. 1986. "Central Problems in the Management of Innovation." Management Science 32 (5): 590-607. doi:10.1287/mnsc.32.5.590.

Voorberg, W. H., V.J.J.M. Bekkers, and L. G. Tummers. 2015. "A systematic review of cocreation and co-production: Embarking on the social innovation journey." Public Management Review 17, no. 9 1333-1357.

Walker, R. M, E. Jeanes, and R. Rowlands. 2001. Managing Public Services Innovation: The Experience of English Housing Associations. Bristol : Policy.

Walker, R. M., C. N. Avellaneda, and F. S. Berry. "Exploring the diffusion of innovation among high and low innovative localities: A test of the Berry and Berry model." Public Management Review 13, no. 1 (2011): 95-125.

*Weber, K. M., B. Heller-Schuh, H. Godoe, and R.Roeste. 2014. "ICT-Enabled System Innovations in Public Services: Experiences from Intelligent Transport Systems." Telecommunications Policy 38 (5/6): 539-557. doi:10.1016/j.telpol.2013.12.004.

*Wigfall, V., E. Monck, and J. Reynolds. 2006. "Putting Programme into Practice: The Introduction of Concurrent Planning into Mainstream Adoption and Fostering Services." British Journal of Social Work 36 (1): 41-55. doi:10.1093/bjsw/bch250.

Windrum, P., and P. M. Koch, eds. 2008. Innovation in Public Sector Services: Entrepreneurship, Creativity and Management. Edward Elgar Publishing.

*Zelenbabic, D. 2015. "Fostering Innovation through Innovation Friendly Procurement Practices: A Case Study of Danish Local Government Procurement." Innovation-The European Journal of Social Science Research 28 (3, SI): 261-281. doi:10.1080/13511610.2015.1056724. 